\title{
Sub muscular bridge plating for pediatric femur fractures - Review of 12 patients
}

\author{
Gaurav Pawar', Nilesh Darawade ${ }^{2, *}$, Yogesh R. Gaikwad ${ }^{3}$ \\ 1 Jurnior Resident III, ${ }^{2}$ Assistant Professor, ${ }^{3}$ Professor, Dept. of Orthopaedics, Smt. Kashibai Navale Medical College Pune, \\ Maharashtra, India \\ *Corresponding Author: Nilesh Darawade \\ Email: drnilesh1@gmail.com
}

\begin{abstract}
Introduction: The treatment of paediatric femoral fractures has been evolving from nonoperative modalities to operative intervention, especially in older children. Different methods of fixation include flexible intramedullary nailing, modified locked intramedullary nailing, external fixation, open compression plating, and sub muscular bridge plating. Treatment of complex paediatric femur diaphyseal fractures is difficult by conventional methods. External fixation can lead to malalignment and refractures, casting is difficult for polytrauma patients and larger children, elastic nails do not provide adequate stability to unstable fractures and metaphyseal areas, and lateral trochanteric entry rigid nails are unsuitable for very proximal and distal fragments and are ideal for older children for the want of larger medullary canal. Sub muscular bridge plating has emerged as a viable alternative procedure. We present our results of sub muscular bridge plating in 12 patients.

Materials and Methods: We retrospectively reviewed 12 patients with pediatric diaphyseal femoral fractures treated with SBP from 2014 to 2016 . The average age was 9 years with follow up of $1 \mathrm{yr}$.

Results: All the children had complete union and could return to full activity. Two patients had superficial infections. There were no cases of significant malalignment or leg length discrepancy. Implant removal was performed in 8 patients without complications. Conclusion: We find sub muscular plating of paediatric femoral fractures to be an effective and reliable procedure. SBP is a minimally invasive technique that allows early mobilization with minimal complications.
\end{abstract}

Keywords: Paediatric femur fractures, Submuscular plating.

\section{Introduction}

Femoral shaft fractures account for $1.4 \%$ to $1.7 \%$ of all fractures seen in paediatric population. ${ }^{1}$ Treatment for paediatric femoral fractures has been evolving from conservative to operative intervention especially in older children, more than 5 years of age.

Children younger than 6 years of age can be managed conservatively by traction and spica cast application. $^{2}$ Increased cost of hospitalization, probability of malalignment and prolonged immobilization due to conservative method has led to shift towards operative intervention in older children. Different modalities described are intramedullary nailing by flexible or rigid nails, external fixation, traditional open reduction and plate fixation and sub muscular bridge plating. Goals of any operative treatment modality are to preserve femoral blood supply, avoid damage to the physis and achieve adequate fracture stability.

Titanium Elastic Nailing System (TENS) is the preferred modality of treatment for children under 11 years. It is suitable for stable midshaft fractures. However proximal and distal fractures, spiral and comminuted fractures and fractures in heavy children (40-45 kg) may have suboptimal outcome with TENS with higher complications. ${ }^{3-5}$ External fixation may lead to refracture, malunion, delayed union, pin tract infections and unsightly scars. ${ }^{6-9}$ Rigid intramedullary nails with piriformis fossa as the entry site raise possibility of damaging the vascular supply to the femoral head, resulting in avascular necrosis. Utilizing nails with greater trochanter entry points also do not completely obviate this problem. ${ }^{10-13}$ There is a risk for growth arrest of the greater trochanter apophysis resulting in coxa valga and heterotopic bone formation if the trochanteric physis is violated. ${ }^{12}$ For fixation with rigid intramedullary nails, medullary canal should be large enough to accommodate width of nail. Rigid nails are thus indicated for shaft fractures in older children with wider medullary canals, but for smaller children inserting intramedullary interlocking nails may not be possible. Fractures in proximal $1 / 3^{\text {rd }}$ and distal $1 / 3^{\text {rd }}$ may not gain adequate stability with intramedullary nails due to smaller length of nail-bone contact. ${ }^{12-15}$ Traditional open reduction and application of compression plate requires long incisions and more soft tissue dissection. Therefore it has a higher risk of infection and delayed healing with a reported reoperation rate of $10 \% .^{16}$

Sub-muscular bridge plating (SBP) for diaphyseal femur fractures was first reported for adult patients in the late 1990s. ${ }^{17}$ As the procedure began to gain acceptance among Orthopaedic surgeons similar principles were applied for treatment of fractures in the pediatric population. The advantages include a minimally invasive, soft tissue preserving approach, relative stability that allows for early ROM and reliable healing. We present our results of SBP in 12 patients with minimum follow up of 1 year.

\section{Materials and Methods}

Our indications for SBP were displaced pediatric femur diaphyseal fractures that were unstable (with multiple fragments or spiral) and/or with a short 
proximal or distal fragment. The contraindications were active infection of the surgical site, open fractures.

Fracture type was classified according to the OTA/AO classification ${ }^{18}$ as follows: A (simple, transverse or short oblique), B (wedge-shaped middle fragment), or C (complex, with multiple fragments).

During a 3-year period, we treated 13 patients (12 boys, 1 girls) with femoral fractures by sub-muscular bridge plating. Mean age at the time of surgery was 9 years (range 5- 14 years). All the available treatment options (conservative and surgical) and the advantages and disadvantages of each option were discussed with parents so that an informed decision could be made. Patients were assessed on admission and kept in balanced Thomas traction until the surgical intervention.

$4.5 \mathrm{~mm}$ narrow low contact dynamic compression plate (LC-DCP) plates were utilized in 6 patients and $4.5 \mathrm{~mm}$ DCP plates in remaining 7 patients. Intraoperatively radiolucent table used with both legs draped free for estimation of length and rotation. Plate was contoured as per location of fracture along length of femur. Care was taken to avoid physeal injury. Depending on fracture site, proximal incision (4-6 centimeters long) was usually made at the level of the vastus ridge on the greater trochanter. Dissection was done to identify plane between muscle mass and periosteum over lateral cortex of femur and this plane was developed distally using a long Cobb's elevator. The plate was slid in this plane from proximal to distal staying epi-periosteal. Position of plate was provisionally secured with a $1.5 \mathrm{~mm} \mathrm{~K}$-wire through the plate hole at one end, utilizing intraoperative imaging [Fig. 1]. The position of the other end of the plate was determined under fluoroscopy and incision was made at that level. Distal incisions were made first when fracture was in distal half of bone and plate was slid from distal to proximal in similar epiperiosteal manner. Fracture was reduced with manipulation and longitudinal traction. We used folded sterile sheets as adjunct for reduction whenever necessary. If reduction was acceptable reduction position of plate was adjusted to maintain plate in good contact with bone and $2^{\text {nd }} \mathrm{K}$-wire was introduced through a hole at the other end of the plate for provisional fixation. After additional evaluation and necessary adjustments were made, 3 cortical screws were inserted in either fragments. In few cases soft tissue interposition made closed reduction difficult and an incision was made at fracture site to achieve reduction with finger manipulation or a bone hook. We did not use any splints in postoperative period.

Postoperatively we mobilized the patients within 13 days as per their comfort, using a walker and with the recommendation to be partial weight bearing for 6 weeks. However it was difficult to get children not to bear weight on affected extremity and many of them were bearing complete weight on operated side in follow up visits.
Follow up visits at clinic were scheduled around 2 weeks, 6 weeks, 3 months, and 8 to 12 months. Radiological union was defined as presence of bridging callus across 3 cortices in orthogonal radiographs. Patients could bear weight without support when radiological union was achieved. We advised avoiding sports for 6 months (depending on the size and quality of callus). We advised implant removal approximately 1 year after injury. Delay in hardware removal is associated with bone overgrowth over the plate, making the surgery more difficult. Patients were advised to avoid strenuous activities for a period of at least 6 weeks after implant removal.

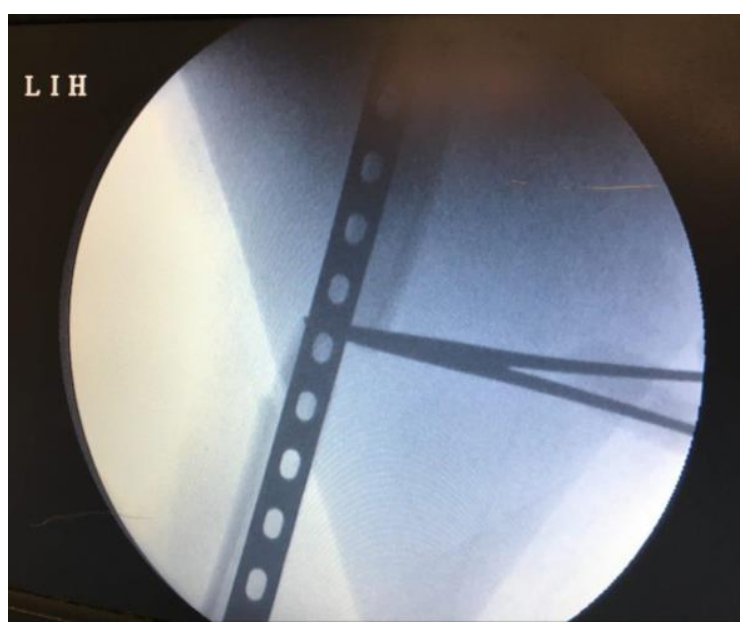

Fig. 1: Intraoperative image for plate positioning

\section{Results}

All fractures united with acceptable alignment without rotational or angular deformity [Fig. 2]. Thirteen consecutive patients between the ages of 5 and 13 years with length unstable [length of fracture more than twice diameter of shaft] femoral shaft fractures participated in the study. One child could not be contacted for final follow up and was excluded from the results. The mean operative time was 82 minutes with average total incision length of $10 \mathrm{~cm}(7-12 \mathrm{~cm}) .10-13$ holes plates were used most frequently. Children were discharged at an average of 8 days after surgery (Range 6-13 days).

In 1 patient fracture site had to be opened in order to obtain reduction as indirect reduction was difficult due to soft tissue interposition. Two patients had superficial infections and responded to intra-venous antibiotics while 3 patients had shortening of $1-1.5 \mathrm{~cm}$. None of the patients with shortening required a shoe lift or had any functional deficit at latest follow up. Implant removal was performed in all patients without complications. [Fig. 3] 
Table 1

\begin{tabular}{|l|c|c|c|c|c|c|}
\hline S. No. & Age (yrs.) & Sex & $\begin{array}{c}\text { Fracture Pattern } \\
\text { (OTA) }\end{array}$ & Plate & $\begin{array}{c}\text { Associated } \\
\text { fractures }\end{array}$ & Complications \\
\hline 1 & 8 & $\mathrm{M}$ & $\mathrm{B}$ & $4.5 \mathrm{DCP}$ & None & None \\
\hline 2 & 9 & $\mathrm{M}$ & $\mathrm{A}$ (short oblique) & $4.5 \mathrm{DCP}$ & None & $12 \mathrm{~mm}$ shortening \\
\hline 3 & 11 & $\mathrm{M}$ & $\mathrm{C}$ & $4.5 \mathrm{DCP}$ & None & Sup. Infection \\
\hline 4 & 7 & $\mathrm{M}$ & $\mathrm{B}$ & $4.5 \mathrm{DCP}$ & Ipsilateral tibia & None \\
\hline 5 & 5 & $\mathrm{M}$ & $\mathrm{A}(\mathrm{transverse})$ & $4.5 \mathrm{DCP}$ & None & None \\
\hline 6 & 10 & $\mathrm{M}$ & $\mathrm{B}$ & $4.5 \mathrm{DCP}$ & None & Sup. Infection \\
\hline 7 & 8 & $\mathrm{M}$ & $\mathrm{A}$ (short oblique) & $4.5 \mathrm{DCP}$ & None & None \\
\hline 8 & 14 & $\mathrm{M}$ & $\mathrm{B}$ & $4.5 \mathrm{LC}-\mathrm{DCP}$ & Ipsilateral clavicle & $8 \mathrm{~mm}$ shortening \\
\hline 9 & 6 & $\mathrm{M}$ & $\mathrm{A}$ (long oblique) & $4.5 \mathrm{LC}-\mathrm{DCP}$ & None & None \\
\hline 10 & 11 & $\mathrm{M}$ & $\mathrm{C}$ & $4.5 \mathrm{LC}-\mathrm{DCP}$ & None & $14 \mathrm{~mm}$ shortening \\
\hline 11 & 8 & $\mathrm{~F}$ & $\mathrm{~A}($ transverse) & $4.5 \mathrm{LC}-\mathrm{DCP}$ & None & None \\
\hline 12 & 9 & $\mathrm{M}$ & $\mathrm{B}$ & $4.5 \mathrm{LC}-\mathrm{DCP}$ & None & None \\
\hline
\end{tabular}

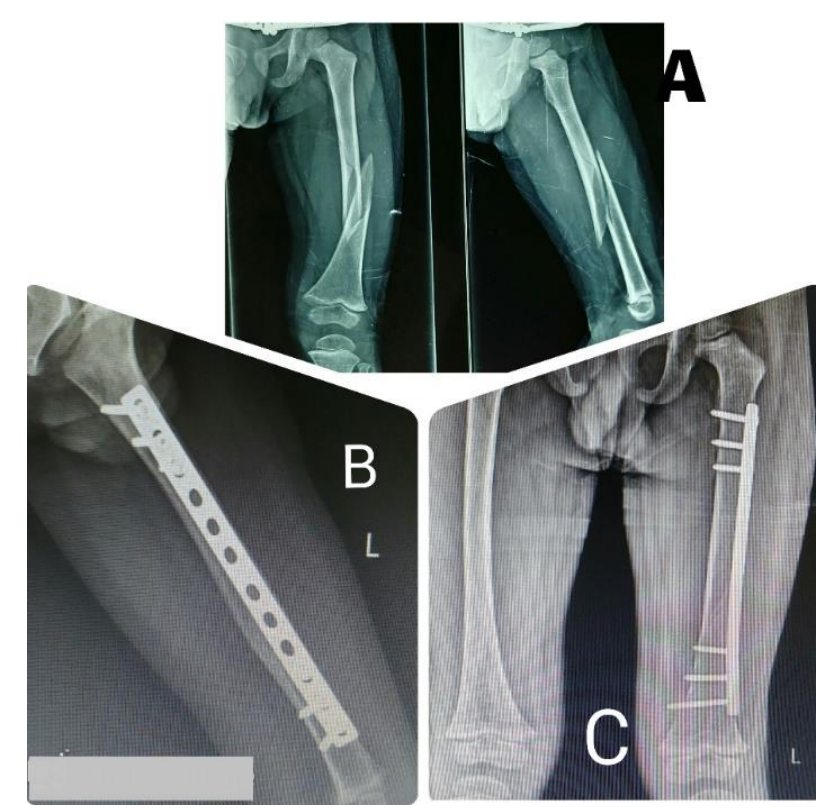

Fig. 2: A. Preop radiograph of 6 yrs. of child with long oblique fracture shaft femur; B \& C. Post op radiographs after sub-muscular bridge plating
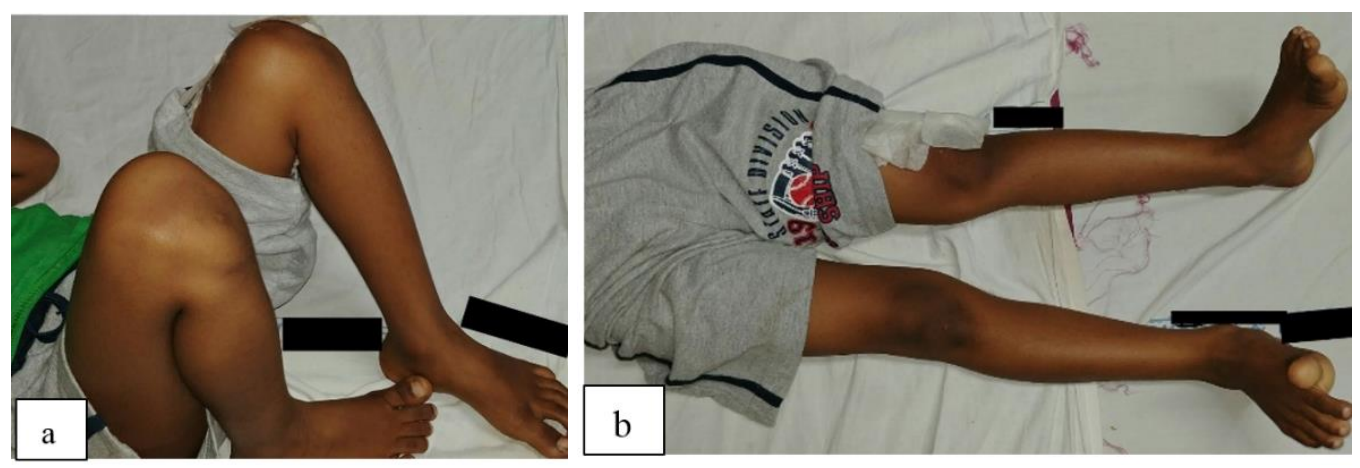


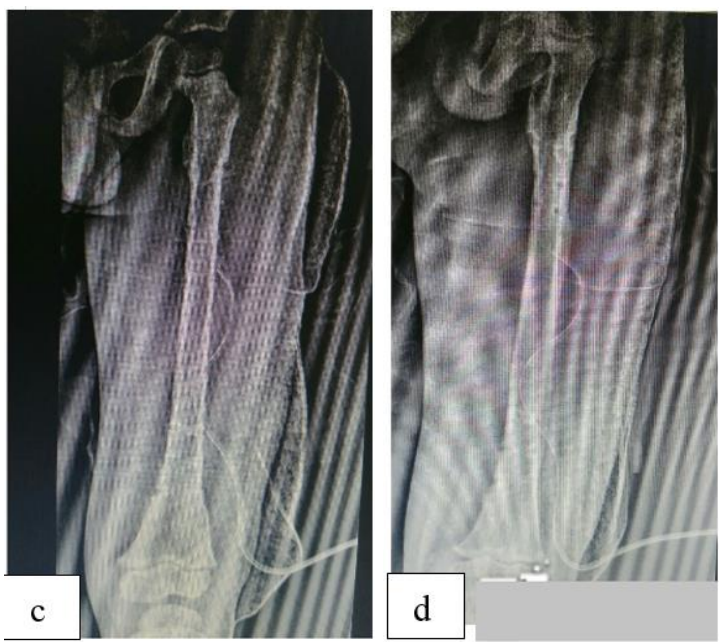

Fig. 3: a \& b. Range of motion after plate removal; c \& d: Postop radiographs after plate removal at 1 year from index surgery

\section{Discussion}

The goals for treatment of femoral shaft fractures in children are - to control alignment and length, the child should be comfortable during the treatment, family of child should be able to negotiate through the period of healing with reasonable convenience, and child should have least negative psychological impact during this phase. ${ }^{19}$ Several treatment options have been described to treat femoral fractures in children: Plaster cast, external fixation and intramedullary nailing using flexible or rigid nails. Cast is cumbersome for older children and patients with multiple injuries. ${ }^{16}$ The treatment of pediatric femoral shaft fractures, particularly in the 6 to 13 years age group, has in recent times moved away from the traditionally conservative approach to a more surgical one. Suggested advantages of internal fixation are less disruption of family life, shorter hospitalization, earlier independent mobilization, and earlier return to school. ${ }^{19}$ External fixation is associated with possibilities of pin tract infection and refracture. ${ }^{17}$ Titanium elastic nailing is probably the most frequently utilized method for fixation of femoral fractures. This method allows fixation of most femoral shaft fractures through small incisions. However, elastic nails are not free of complications. ${ }^{20}$ Conventional compression plating requires longer incision and more soft tissue handling. This increases risk of infection and possibility of delayed union due to loss of soft tissue attachments of bone. ${ }^{16}$

Sub-muscular bridge plating provides adequate stability while preserving soft tissue cover to bone thus helping the process of bone healing. We found the stability achieved to be consistent as corroborated by literature. ${ }^{22-27}$ Even in complex fractures, fracture alignment and leg length was reliably achieved. None of our patients had clinically significant malrotation or shortening. In comminuted and length unstable fractures, flexible nails are associated with a high rate of malunion. ${ }^{3-6,20,27-31}$ Sink et al. ${ }^{20}$ reported 8 of their 39 patients $(21 \%)$ required unplanned surgeries and found 10 of the 15 patients $(66 \%)$ in the unstable fracture group had either fracture shortening or angulation. Moroz et al. ${ }^{32}$ noted that patients weighing more than $49 \mathrm{kgs}$ were prone to poor outcome with flexible nails. The results with sub muscular bridge plating were not affected by patient age, weight or site of fracture. It can be performed even in smaller children irrespective of the size of their medullary canals which can be a limiting factor for intramedullary nail fixation. Keeler et $\mathrm{al} .{ }^{33}$ reported average age of 12.9 years in their series for antegrade nails.

Fixation of fractures in proximal and distal $1 / 3^{\text {rd }}$ is more challenging than midshaft fractures. With intramedullary nails, stability may be inadequate due to shorter bone nail contact. Sub-muscular plating reliably provides adequate stability in these fractures.

This series indicates that sub-muscular bridge plating is a reliable modality to treat unstable femoral shaft fractures. It is a minimally invasive technique with resultant small scars and does not disrupt the fracture biology. It allows for early mobilization and discharge. Bridge plating was performed in 12 patients in this study with good results. The reduction was maintained and all fractures went onto unite within 2-4 months. There were no significant malalignments or leg length discrepancies and all patients returned to full activities. Disadvantages of this modality are necessity of second surgery for implant removal, surgical scars could be still longer compared to incisions made for intramedullary flexible nails. Limitations in this study include lack of a comparison group and relatively small study population.

\section{Conclusion}

We find sub muscular bridge plating of paediatric femoral fractures with contoured plates to be an effective and safe procedure. Sub muscular bridge plating provides reliable fixation and healing for pediatric femur fractures and is a minimally invasive technique that allows for early mobilization. 


\section{References}

1. Rockwood and Wilkin's Fractures in children, $6^{\text {th }}$ Edition. Lippincott Williams \& Wilkins, Philadelphia, USA. 2006;894.

2. Heyworth BE, Galano GJ, Vitale MA, Vitale MG. Management of closed femoral shaft fractures in children, ages 6 to 10: national practice patterns and emerging trends. J Pediatr Orthop. 2004;24:455-459.

3. Flynn JM, Hresko T, Reynolds RA, Blasier RD, Davidson R, Kasser J. Titanium elastic nails for pediatric femur fractures: a multicenter study of early results with analysis of complications. J Pediatr Orthop. 2001;21:48.

4. Flynn JM, Luedtke L, Ganley TJ, Pill SG. Titanium elastic nails for pediatric femur fractures: lessons from the learning curve. Am J Orthop. 2002; 31:71-74.

5. Heinrich SD, Drvaric DM, Darr K, MacEwen GD. The operative stabilization of pediatric diaphyseal femur fractures with flexible intramedullary nails: a prospective analysis. J Pediatr Orthop. 1994;14:501-507.

6. Anglen JO, Choi L. Pediatric femoral shaft fractures. $J$ Orthop Trauma. 2005;19:724-733.

7. Miner T, Carroll KL. Outcomes of external fixation of pediatric femoral shaft fractures. J Pediatr Orthop. 2000;20:405-410.

8. Poolman RW, Kocher MS, Bhandari M. Pediatric femoral fractures: a systematic review of 2422 cases. J Orthop Trauma. 2006;20:648-654.

9. Skaggs DL, Leet AI, Money MD, Shaw BA, Hale JM, Tolo VT. Secondary fractures associated with external fixation in pediatric femur fractures. J Pediatr Orthop. 1999;19:582-586.

10. Buford D Jr, Christensen K, Weatherall P. Intramedullary nailing of femoral fractures in adolescents. Clin Orthop Relat Res. 1998;350:85-89.

11. Heyworth BE, Suppan CA, Kramer DE, Yen YM. Management of pediatric diaphyseal femur fractures. Curr Rev Musculoskelet Med. 2012 February 9 [Epub ahead of print].

12. Hosalkar HS, Pandya NK, Cho RH, Glaser DA, Moor MA, Herman MJ. Intramedullary nailing of pediatric femoral shaft fracture. J Am Acad Orthop Surg. 2011;19:472-481.

13. MacNeil JA, Francis A, El-Hawary R. A systematic review of rigid, locked, intramedullary nail insertion sites and avascular necrosis of the femoral head in the skeletally immature. J Pediatr Orthop. 2011;31:377-380.

14. Gordon JE, Khanna N, Luhmann SJ, Dobbs MB, Ortman MR, Schoenecker PL. Intramedullary nailing of femoral fractures in children through the lateral aspect of the greater trochanter using a modified rigid humeral intramedullary nail: preliminary results of a new technique in 15 children. J Orthop Trauma. 2004;18:416422.

15. Kanlic E, Cruz M. Current concepts in pediatric femur fracture treatment. Orthopedics. 2007;30:1015-1019.

16. Caird MS, Mueller KA, Puryear A, Farley FA. Compression plating of pediatric femoral shaft fractures. J Pediatr Orthop. 2003;23:448-452.

17. Chrisovitsinos JP, Xenakis T, Papakostides KG, Skaltsoyannis N, Grestas A, Soucacos PN. Bridge plating osteosynthesis of 20 comminuted fractures of the femur. Acta Orthop Scand Suppl. 1997;275:72-76.

18. Marsh JL, Slongo TF, Agel J, Broderick JS, Creevey W, DeCoster TA, Prokuski L, Sirkin MS, Ziran B, Henley B, Audige ' L. Fracture and dislocation classification compendium - 2007: Orthopaedic Trauma Association classification, database and outcomes committee. $J$ Orthop Trauma. 2007;21(10 suppl):S1-S133.

19. Campbell's Operative Orthopaedics, $12^{\text {th }}$ Edition, Elsevier Mosby, Philadelphia, USA. Chapter 36, pg 1461.

20. Sink EL, Gralla J, Repine M. Complications of pediatric femur fractures treated with titanium elastic nails: a comparison of fracture types. J Pediatr Orthop. 2005;25:577-580

21. Kocher MS, Sink EL, Blasier RD, Luhmann SJ, Mehlman CT, Scher DM, Matheney T, Sanders JO, Watters WC 3rd, Goldberg MJ, Keith MW, Haralson RH 3rd, Turkelson CM, Wies JL, Sluka P, Hitchcock K. Treatment of pediatric diaphyseal femur fractures. $J \mathrm{Am}$ Acad Orthop Surg. 2009;17:718-725.

22. Hedequist D, Bishop J, Hresko T. Locking plate fixation for pediatric femur fractures. J Pediatr Orthop. 2008;28:6-9.

23. Hedequist DJ, Sink E. Technical aspects of bridge plating for pediatric femur fractures. J Orthop Trauma. 2005;19:276-279.

24. Kanlic EM, Anglen JO, Smith DG, Morgan SJ, Pesa 'ntez RF. Advantages of submuscular bridge plating for complex pediatric femur fractures. Clin Orthop Relat Res. 2004;426:244-251.

25. Kuremsky MA, Frick SL. Advances in the surgical management of pediatric femoral shaft fractures. Curr Opin Pediatr. 2007;19:51-57.

26. Sink EL, Faro F, Polousky J, Flynn K, Gralla J. Decreased complications of pediatric femur fractures with a change in management. $J$ Pediatr Orthop. 2010;30:633-637.

27. Ellis HB, Ho CA, Podeszwa DA, Wilson PL. A comparison of locked versus nonlocked Enders rods for length unstable pediatric femoral shaft fractures. $J$ Pediatr Orthop. 2011;31:825-833.

28. Flynn JM, Schwend RM. Management of pediatric femoral shaft fractures. J Am Acad Orthop Surg. 2004;12:347-359.

29. Garner MR, Bhat SB, Khujanazarov I, Flynn JM, Spiegel D. Fixation of length-stable femoral shaft fractures in heavier children: flexible nails vs rigid locked nails. $J$ Pediatr Orthop. 2011;31:11-16.

30. Jencikova-Celerin L, Phillips JH, Werk LN, Wiltrout SA, Nathanson I. Flexible interlocked nailing of pediatric femoral fractures: experience with a new flexible interlocking intramedullary nail compared with other fixation procedures. J Pediatr Orthop. 2008;28:864-873.

31. Wall EJ, Jain V, Vora V, Mehlman CT, Crawford AH. Complications of titanium and stainless-steel elastic nail fixation of pediatric femoral fractures. J Bone Joint Surg Am. 2008;90:1305-1313.

32. Moroz LA, Launay F, Kocher MS, Newton PO, Frick SL, Sponseller PD, Flynn JM. Titanium elastic nailing of the femur in children: predictors of complications and poor outcomes. J Bone Joint Surg Br. 2006;88:1361-1366.

33. Keeler KA, Dart B, Luhmann SJ, Schoenecker PL, Ortman MR, Dobbs MB, Gordon JE. Antegrade intramedullary nailing of pediatric femoral fractures using an interlocking pediatric femoral nail and a lateral trochanteric entry point. J Pediatr Orthop. 2009;29:345351.

How to cite this article: Pawar G, Darawade N, Gaikwad YR. Sub muscular bridge plating for pediatric femur fractures - Review of 12 patients. Indian J Orthop Surg. 2018;4(3):240-244. 